\title{
Ambient Gamma Levels in the Seaside Regions of Thangasherry, Kerala
}

\author{
S. Monica \\ Center for Advanced Research in Physical Sciences, Department of Physics, \\ Fatima Mata National College (Autonomous), Kollam, India
}

Available online at: www.isroset.org

Received:18/Sept/2018, Accepted:03/Oct/2018, Online: 31/Oct/2018

\begin{abstract}
Indoor and outdoor gamma dose rates were evaluated along the coastal regions of Thangasherry, Kollam district, Kerala through direct measurements using a GM based gamma dose survey meter, time integrated measurement using $\mathrm{CaSO}_{4}$ :Dy based thermo luminescent dosimeters (TLDs) and gamma spectrometry of soil samples. The mean value of total annual effective dose rate observed were $0.26 \pm 0.01 \mathrm{mSv} / \mathrm{yr}$, respectively with an indoor to outdoor dose ratio of 0.54 . The radioactivity content in the soil samples, the absorbed dose rate, annual effective dose equivalent, radium equivalent activity, internal and external hazard indices , the representative gamma index and alpha index ( $\mathrm{I}_{\text {gamma }}$ and $\mathrm{I}_{\text {alpha }}$ ), the annual gonad dose equivalent (AGDE) and the excess lifetime cancer risk (ELCR) were determined and compared with recommended values. Correlation study showed that the dose estimated from the TLDs is better correlated with that measured directly using the portable survey meter. The results of natural radioactivity levels in the soil samples has been compared with the levels reported in other Indian cities as well as other parts of the world.
\end{abstract}

Keywords: Gamma dose, Thermoluminescence, effective dose

\section{INTRODUCTION}

The knowledge of distribution of radionuclides and radiation levels in the environment is important for assessing the effects of radiation exposure due to both terrestrial and extraterrestrial sources. Human beings are constantly exposed to natural sources of ionizing radiations in nature. The natural background radiations have both terrestrial and extra-terrestrial origins. The extra-terrestrial radiation is largely due to cosmic rays. The worldwide average radiation dose at sea level due to cosmic rays is $31 \mathrm{nGy} \mathrm{h}^{-1}[1]$ and that for India is $32 \mathrm{nGy} \mathrm{h}^{-1}$ [2], the dose increases with the altitude. The terrestrial gamma rays are essentially derived from ${ }^{40} \mathrm{~K}$ and radionuclides belonging to ${ }^{238} \mathrm{U}$ and ${ }^{232} \mathrm{Th}$ series that are present in the earth's crust. The worldwide average value for outdoor gamma absorbed dose rate in air due to terrestrial sources is $54 \mathrm{nGy} \mathrm{h}-{ }^{1}$ and the relative contributions of ${ }^{40} \mathrm{~K},{ }^{238} \mathrm{U}$, and ${ }^{232} \mathrm{Th}$ to this dose are about $35 \%, 25 \%$, and $40 \%$, respectively [3].

The variation of terrestrial radiation is typically larger than that of cosmic rays. There are regions in the world where the outdoor terrestrial radiation exceeds substantially the average value due to the enrichment of certain radioactive minerals leading to the formation of what are known as high background areas. The presence of high background areas has been reported in several countries like China, Iran, Germany, USA, Brazil, and India [1].

The main objective of this study was to measure the indoor and outdoor radiation dose rates and calculate annual effective dose (AED) received by the people along the coastal regions of Thangasherry, Kollam district, Kerala. The activity concentration of radioactive elements such as ${ }^{226} \mathrm{Ra}$, ${ }^{232} \mathrm{Th},{ }^{40} \mathrm{~K}$ and gamma ray absorbed dose in soil samples was also determined using gamma-ray spectrometry. The values obtained were compared with that of the world average as well as with the other values reported in literature. A brief review of radiological survey in some areas as carried out within and outside the country by some researchers with result obtained is shown in Table 1. A comparative study of in situ measurements of gamma dose rates using portable dosimeters and integrated measurements over a period of 90 days using TLDs, and the correlation study showed that the dose estimated from the TLDs is better correlated with that measured directly using the portable survey meter. 
Table 1:A review of radiological survey in some areas as carried out within and outside the country.

\begin{tabular}{|c|c|c|}
\hline Region & Annual effective dose & Reference \\
\hline India & $2.3 \mathrm{mSv} / \mathrm{yr}$ & Ramachandran et al., 2011 \\
\hline Iran & $1.73 \mathrm{mSv}$ & Sadegh et al., 2012 \\
\hline Jos, Nigeria & $2.063 \mathrm{mSv} / \mathrm{yr}$ & Jwanbot et al., 2012 \\
\hline Adeokuta, Nigeria & $(0.19-1.64) \mathrm{mSv} / \mathrm{yr}$ & Farai and Vincent, 2006 \\
\hline Yazd Province & $1.03 \mathrm{mSv} / \mathrm{yr}$ & Bouzarjomehri et al., 2005 \\
\hline Abeokuta, Nigeria & $68.74 \mu \mathrm{Sv} / \mathrm{yr}$ & Okeyode et al., 2010 \\
\hline
\end{tabular}

\section{MATERIALS AND METHODS}

\subsection{Selection of the measurement sites}

The gamma background radiation measurements were performed both indoor and outdoor along the coastal region of Thangasherry ,kollam district,Kerala.

\subsection{Gamma absorbed dose measurements using portable dose surveymeter}

The ambient gamma absorbed dose rates were measured in the sampling locations using GM tube-based gamma dosimeter (POLIMASTER PM 1405). This device can detect gamma rays in the energy range of $0.05-3 \mathrm{MeV}$ and the dose rate measurement range is $0.1 \mu \mathrm{Sv} / \mathrm{h}$ to 100

$\mathrm{mSv} / \mathrm{h}$. The gamma radiation levels were measured both inside and outside the dwellings at $1 \mathrm{~m}$ above the ground. About 20 readings were taken at different points in each location.

\subsection{Gamma absorbed dose measurements using Thermo luminescentdosimeter (TLD)}

TLD is a passive device for the measurement of gamma dose and in this the dose is acquired and stored for a long period of time until the system is stimulated by heat. The advantage of this system is that since it acquires the dose continuously the variation of dose during different periods of time is averaged out. Therefore, the long-term integrated measurements of gamma dose rates are carried out using thermo luminescent dosimeters based on CaSO4:Dy phosphor. The dosimeters were specially designed to measure the environmental gamma radiation by the Bhabha Atomic Research Centre (BARC), Mumbai Chougaonkar et al. [4]. The details of the preparation of the TLD dosimeters and calibration are published elsewhere by Chougaonkar et al. [4]. The TLDs were deployed inside 20 dwellings and 20 outdoor locations for a time period of 90 days. Inside the dwellings, they were installed at least $1 \mathrm{~m}$ away from the walls and about $3 \mathrm{~m}$ above the floor. In the outdoors they were installed just outside the dwelling at a similar height. The retrieved dosimeters were analyzed using the automatic TLD reader (LLRRL,Kollam) and the absorbed dose was arrived at using standardized methodology [4]. An appropriate number of TLDs were kept as control TLDs at both laboratory and field location to determine the control dose at both these locations and transit TLDs were used to determine the transit dose. At the time of installing and retrieving the TLDs, the gamma dose rates were measured using the survey meter, as detailed in the earlier section.

2.4. Soil sample collection and measurement of radionuclide activity Concentrations

Twenty soil samples were collected along the coastal regions of Thangasherry,kollam district. All collected soil samples were stored in sealed polyethylene bags, labelled and then transported to the laboratory. In the laboratory, after removing the stones and organic materials, the samples were dried in an oven at $110^{\circ} \mathrm{C}$ for $24 \mathrm{~h}$ to remove the moisture content and then crushed to pass through a 150-mesh sieve to homogenise it.Finally, weighed samples were sealed in gastight, radon-impermeable, trap-shaped polyethylene containers. These samples were stored in a dry room at room temperature for 30 days before counting radium and thorium daughter products to attain radioactive equilibrium.

The concentrations of the natural radionuclides ${ }^{226} \mathrm{Ra},{ }^{232} \mathrm{Th}$ and ${ }^{40} \mathrm{~K}$ in soil samples were determined using a $5 \mathrm{X} 5 \mathrm{~cm}$ $\mathrm{NaI}(\mathrm{Tl})$ gamma ray spectrometric system with $8 \%$ energy resolution $\left({ }^{137} \mathrm{Cs} 661 \mathrm{keV}\right)$. The detector is maintained in a vertical position in a lead cylindrical shield. The detector was coupled to a 256 multichannel pulse-height analyser, and the system was calibrated for the gamma energy range $80 \mathrm{keV}-3.2 \mathrm{MeV}$. The energy region for ${ }^{40} \mathrm{~K}, 1.46 \mathrm{MeV}$ gamma rays, ${ }^{226} \mathrm{Ra}, 1.76 \mathrm{MeV}$ gamma rays $\left({ }^{214} \mathrm{Bi}\right)$ and ${ }^{232} \mathrm{Th}$, $2.61 \mathrm{MeV}$ gamma rays $\left({ }^{208} \mathrm{Tl}\right)$ were chosen as $1.30-1.60$, 1.62-2.00 and 2.45-2.90 MeV, respectively. Detector calibration and content calculations have been described in detail previously. All samples were counted for $10000 \mathrm{~S}$.

\subsection{Estimation of Radium Equivalent,absorbed dose,Effective doses,Annual Gonadal dose,cancer risk and representative level indices from soil radioactivity measurements}

\subsubsection{Radium equivalent activity}

It was calculated through the following relation [5]: $R a_{e q}=$ $C_{R a}+1.43 C_{T h}+0.07 C_{K}$, where $\mathrm{C}_{\mathrm{Ra}}, \mathrm{C}_{\mathrm{Th}}$ and $\mathrm{C}_{\mathrm{K}}$ are the activity concentrations of ${ }^{226} \mathrm{Ra},{ }^{232} \mathrm{Th}$ and ${ }^{40} \mathrm{~K}$ in $\mathrm{Bq} / \mathrm{kg}$, 
respectively. While defining $\mathrm{Ra}_{\mathrm{eq}}$ activity, it has been assumed that $370 \mathrm{~Bq} / \mathrm{kg}{ }^{226} \mathrm{Ra}$ or $259 \mathrm{~Bq} / \mathrm{kg}{ }^{232} \mathrm{Th}$ or 4810 $\mathrm{Bq} / \mathrm{kg}{ }^{40} \mathrm{~K}$ produce the same gamma dose rate.

\subsubsection{Calculation of air-absorbed dose rate}

The external terrestrial gamma radiation absorbed dose rate in air at a height of about $1 \mathrm{~m}$ above the ground was calculated by using the conversion factor of $0.0414 \mathrm{nGy} \mathrm{h}^{-}$ ${ }^{1} / \mathrm{Bq} \mathrm{kg}^{-1}$ for ${ }^{40} \mathrm{~K}, 0.461 \mathrm{nGy} \mathrm{h}^{-1} / \mathrm{Bq} \mathrm{kg}^{-1}$ for ${ }^{226} \mathrm{Ra}$, and 0.623 nGy h ${ }^{-1} / \mathrm{Bq} \mathrm{kg}^{-1}$ for ${ }^{232} \mathrm{Th}$ [UNSCEAR,1993], assuming that ${ }^{137} \mathrm{Cs}$, ${ }^{90} \mathrm{Sr}$ and the ${ }^{235} \mathrm{U}$ decay series can be neglected as they contribute very little to the total dose from environmental background.

$$
D\left(n G y h^{-1}=0.461 C_{R a}+0.623 C_{T h}+0.041 C_{k}\right.
$$

where, $\mathrm{C}_{\mathrm{Ra}}, \mathrm{C}_{\mathrm{Th}}$ and $\mathrm{C}_{\mathrm{K}}$ are the activity concentrations (Bq $\mathrm{kg}^{-1}$ ) of radium, thorium and potassium in the samples.

\subsubsection{Calculation of annual effective dose}

Annual estimated average effective dose equivalent received by a member was calculated using a conversion factor of 0.7 Sv $\mathrm{Gy}^{-1}$, which was used to convert the absorbed rate to human effective dose equivalent with an outdoor occupancy of $20 \%$ and $80 \%$ for indoors [UNSCEAR ,1993].

$$
\begin{aligned}
\operatorname{Indoor}(n S v)= & (\text { Absorbed Dose }) n G y h^{-1} \times 8760 h \times 0.8 \\
& \times 0.7 S v G y^{-1}
\end{aligned}
$$

$$
\begin{aligned}
\operatorname{Outdoor}(n S v)= & (\text { Absorbed Dose }) n G y h^{-1} \times 8760 h \\
\times 0.2 \times 0.7 \text { SvGy } &
\end{aligned}
$$

\subsection{Estimation of Radium Equivalent, absorbed dose, Effective doses, Annual Gonadal dose, cancer risk and representative level indices from soil radioactivity measurements}

\subsubsection{Radium equivalent activity}

It was calculated through the following relation [5]: $R a_{e q}=$ $C_{R a}+1.43 C_{T h}+0.07 C_{K}$ where $\mathrm{C}_{\mathrm{Ra}}, \mathrm{C}_{\mathrm{Th}}$ and $\mathrm{C}_{\mathrm{K}}$ are the activity concentrations of ${ }^{226} \mathrm{Ra},{ }^{232} \mathrm{Th}$ and ${ }^{40} \mathrm{~K}$ in $\mathrm{Bq} / \mathrm{kg}$, respectively. While defining $\mathrm{Ra}_{\mathrm{eq}}$ activity, it has been assumed that $370 \mathrm{~Bq} / \mathrm{kg}{ }^{226} \mathrm{Ra}$ or $259 \mathrm{~Bq} / \mathrm{kg}{ }^{232} \mathrm{Th}$ or 4810 $\mathrm{Bq} / \mathrm{kg}{ }^{40} \mathrm{~K}$ produce the same gamma dose rate.

\subsubsection{Calculation of air-absorbed dose rate}

The external terrestrial gamma radiation absorbed dose rate in air at a height of about $1 \mathrm{~m}$ above the ground was calculated by using the conversion factor of $0.0414 \mathrm{nGy} \mathrm{h}^{-}$ ${ }^{1} / \mathrm{Bq} \mathrm{kg}^{-1}$ for ${ }^{40} \mathrm{~K}, 0.461 \mathrm{nGy} \mathrm{h}^{-1} / \mathrm{Bq} \mathrm{kg}^{-1}$ for ${ }^{226} \mathrm{Ra}$, and 0.623 nGy h ${ }^{-1} / \mathrm{Bq} \mathrm{kg}^{-1}$ for ${ }^{232} \mathrm{Th}$ [UNSCEAR,1993], assuming that

${ }^{137} \mathrm{Cs},{ }^{90} \mathrm{Sr}$ and the ${ }^{235} \mathrm{U}$ decay series can be neglected as they contribute very little to the total dose from environmental background.

$$
D\left(n G y h^{-1}=0.461 C_{R a}+0.623 C_{T h}+0.041 C_{k}\right.
$$

where, $\mathrm{C}_{\mathrm{Ra}}, \mathrm{C}_{\mathrm{Th}}$ and $\mathrm{C}_{\mathrm{K}}$ are the activity concentrations $(\mathrm{Bq}$ $\mathrm{kg}^{-1}$ ) of radium, thorium and potassium in the samples.

\subsubsection{Calculation of annual effective dose}

Annual estimated average effective dose equivalent received by a member was calculated using a conversion factor of 0.7 $\mathrm{Sv} \mathrm{Gy}^{-1}$, which was used to convert the absorbed rate to human effective dose equivalent with an outdoor occupancy of $20 \%$ and $80 \%$ for indoors [UNSCEAR ,1993].

$$
\begin{aligned}
& \text { Indoor }(n S v)=(\text { Absorbed Dose }) n G y h^{-1} \times 8760 h \times 0.8 \\
& \times 0.7 S v G y^{-1} \\
& \text { Outdoor }(n S v)=(\text { Absorbed Dose }) n G y h^{-1} \times 8760 h \\
& \times 0.2 \times 0.7 S v G y^{-1}
\end{aligned}
$$

2.5.4.External hazard index $\left(\mathrm{H}_{\mathrm{ex}}\right)$

The external hazard index Hex can be calculated by the following equation:

$$
H_{\text {ext }}=\frac{C_{R a}}{370}+\frac{C_{T h}}{259}+\frac{C_{K}}{4810} \leq 1
$$

where $\mathrm{C}_{\mathrm{Ra}}, \mathrm{C}_{\mathrm{Th}}$ and $\mathrm{C}_{\mathrm{K}}$ are the activity concentrations of ${ }^{226} \mathrm{Ra},{ }^{232} \mathrm{Th}$ and ${ }^{40} \mathrm{~K}$ in $\mathrm{Bq} / \mathrm{kg}$, respectively. The value of this index must be less than the unity in order to keep the radiation hazard to be insignificant. The maximum value of Hex equal to unity corresponds to the upper limit of $\mathrm{Ra}_{\mathrm{eq}}$ $(370 \mathrm{~Bq} / \mathrm{kg})$.

\subsubsection{Internal Hazard Index}

The internal hazard index $\mathrm{H}_{\text {in }}$ can be calculated by the following Equation:

$$
H_{\text {in }}=\frac{C_{R a}}{185}+\frac{C_{T h}}{259}+\frac{C_{K}}{4810}
$$

$H_{\text {in }}$ must be less than unity to have negligible hazardous effects of carcinogenic radon and its short lived progeny to the respiratory.

\subsubsection{Representative Level index}

\subsubsection{Excess lifetime cancer risk}

Excess lifetime cancer risk (ELCR) was calculated using the following equation and presented in Table 4 .

$$
E L C R=A E D E \times R F \times D L
$$

where AEDE, DL and RF are the annual effective dose equivalent, duration of life (70 y) and risk factor $\left(\mathrm{Sv}^{-1}\right)$, fatal cancer risk per sievert. For stochastic effects, ICRP 60 uses values of 0.05 for the public(12).

\subsubsection{Annual gonadal dose equivalent}


The annual gonadal dose equivalent (AGDE, $\mathrm{mSv}^{-1}$ ) due to the specific activities of ${ }^{226} \mathrm{Ra},{ }^{232} \mathrm{Th}$ and ${ }^{40} \mathrm{~K}$ was calculated using the following formula(13):

$$
A G D E=3.09 C_{R a}+4.19 C_{T h}+0.314 C_{K}
$$

The average values of AGDE are presented in Table 4 .

The representative level index $I_{r \gamma}$ of the soil is used to estimate the level of gamma radiation hazard associated with natural emitters in the soil. It was calculated using the relation:

$$
I_{r \gamma}=\frac{C_{R a}}{1500 B q K g^{-1}}+\frac{C_{T h}}{100 B q K g^{-1}}+\frac{C_{K}}{1500 B q K g^{-1}}
$$

The representative level index must be lower than unity in order to keep the radiation hazard insignificant.

\section{RESULTS AND DISCUSSION}

\subsection{Gamma absorbed dose rates}

The indoor and outdoor gamma absorbed dose rates along the coastal region of Thangasherry ,kollam district measured using portable dose surveymeter, are presented in Table 1, and the doses measured using the TLDs are also presented in Table 1. The indoor gamma dose, measured using the survey meter, varied in the range of $(51.2-67.2) \mathrm{nGy} \mathrm{h}^{-1}$ with the mean value of $55.2 \pm 7 \mathrm{nGy} \mathrm{h}^{-1}$, and outdoor gamma dose varied in the range of $(117.2-155.9) \mathrm{nGy} \mathrm{h}^{-1}$ with the mean value of $138.2 \pm 10 \mathrm{nGy} \mathrm{h}^{-1}$. Similarly, the mean values of the doses measured using TLDs were $56.2 \pm 4 \mathrm{nGy} \mathrm{h}^{-1}$ and 135.2 $\pm 7 \mathrm{nGy} \mathrm{h}^{-1}$, respectively, for indoor and outdoor. These results show that the indoor and outdoor dose rates were comparable to each other and the difference between them is $<10 \%$. Also, the mean value of the dose for the entire region was higher when compared to the values (mean of $59 \mathrm{nGy} \mathrm{h}^{-}$ ${ }^{1}$ in the range of 18-93 $\mathrm{nGy} \mathrm{h}^{-1}$ ) given in UNSECAR [9] for different countries and with the all India mean value $(89 \mathrm{nGy}$ $\mathrm{h}^{-1}$ in the range of 27-3051 $\mathrm{nGy} \mathrm{h}^{-1}$ ) reported by Nambi et al. [2].

\subsection{Indoor and outdoor annual effective dose}

From the hourly dose rate, the annual effective dose was computed using the indoor occupancy factor of 0.8 and the outdoor occupancy factor of 0.2 [1] and these are also presented in Tables

1 and 2 . The total annual effective dose thus calculated from the survey meter data had mean values of $0.26 \pm 0.01 \mathrm{mSv} \mathrm{y}^{-1}$ (Table 1) and the corresponding dose values computed from TLD data had mean values of $.28 \pm 0.09 \mathrm{mSv} \mathrm{y}^{-1}$ (Table 1 ). Nambi et al. [2] found the dose levels in India, except HBRAs in the states of Kerala and

Tamil Nadu, to be $0.44 \pm 0.13 \mathrm{mSv} \mathrm{a}^{-1}$. Thus, the total gamma ray dose is higher than the averagevalue for normal background regions of India.

\begin{tabular}{|c|c|c|c|c|c|c|c|c|}
\hline \multirow[t]{2}{*}{ Location } & \multirow[t]{2}{*}{$\begin{array}{l}\text { Sample } \\
\text { code }\end{array}$} & \multicolumn{2}{|c|}{$\begin{array}{l}\text { Gamma dose } \\
\text { rate(nGy/h) } \\
\text { (measured using } \\
\text { Surveymeter) }\end{array}$} & \multicolumn{2}{|c|}{$\begin{array}{l}\text { Gamma dose } \\
\text { rate(nGy/h) } \\
\text { (measured using } \\
\text { TLD) }\end{array}$} & \multicolumn{2}{|c|}{$\begin{array}{l}\text { Annual effective dose } \\
(\mathrm{mSv} / \mathrm{y})\end{array}$} & \multirow[t]{2}{*}{$\begin{array}{l}\text { Reduction } \\
\text { Co-efficient }\end{array}$} \\
\hline & & Indoor & outdoor & Indoor & outdoor & Surveymeter & TLD & \\
\hline \multirow{15}{*}{ Thangasherry } & THA1 & 55.2 & 120.5 & 56.3 & 119.3 & 0.27 & 0.27 & 0.45 \\
\hline & THA2 & 59.5 & 124.5 & 60.6 & 123.3 & 0.29 & 0.29 & 0.47 \\
\hline & THA3 & 52.9 & 132.5 & 54.1 & 131.3 & 0.25 & 0.26 & 0.39 \\
\hline & THA4 & 60.2 & 134.8 & 61.3 & 133.7 & 0.29 & 0.31 & 0.44 \\
\hline & THA5 & 65.2 & 115.8 & 66.3 & 114.6 & 0.31 & 0.32 & 0.56 \\
\hline & THA6 & 69.5 & 117.6 & 70.6 & 116.4 & 0.34 & 0.34 & 0.59 \\
\hline & THA7 & 54.2 & 126.4 & 55.3 & 125.2 & 0.26 & 0.27 & 0.42 \\
\hline & THA8 & 50.2 & 130.4 & 51.3 & 129.2 & 0.24 & 0.25 & 0.38 \\
\hline & THA9 & 52.8 & 148.6 & 54.5 & 147.4 & 0.25 & 0.26 & 0.35 \\
\hline & THA10 & 55.5 & 145.7 & 56.6 & 144.6 & 0.27 & 0.27 & 0.38 \\
\hline & THA11 & 62.8 & 150.2 & 64.4 & 149.1 & 0.31 & 0.31 & 0.41 \\
\hline & THA12 & 64.8 & 119.8 & 66.9 & 118.6 & 0.31 & 0.32 & 0.54 \\
\hline & THA13 & 67.9 & 136.5 & 69.1 & 135.3 & 0.33 & 0.33 & 0.49 \\
\hline & THA14 & 68.4 & 145.5 & 69.5 & 144.3 & 0.33 & 0.34 & 0.47 \\
\hline & THA15 & 54.8 & 147.8 & 56.4 & 146.6 & 0.26 & 0.27 & 0.37 \\
\hline
\end{tabular}

Table 1: Indoor and outdoor gamma absorbed dose rates (measured using portable survey meter and TLDs). 


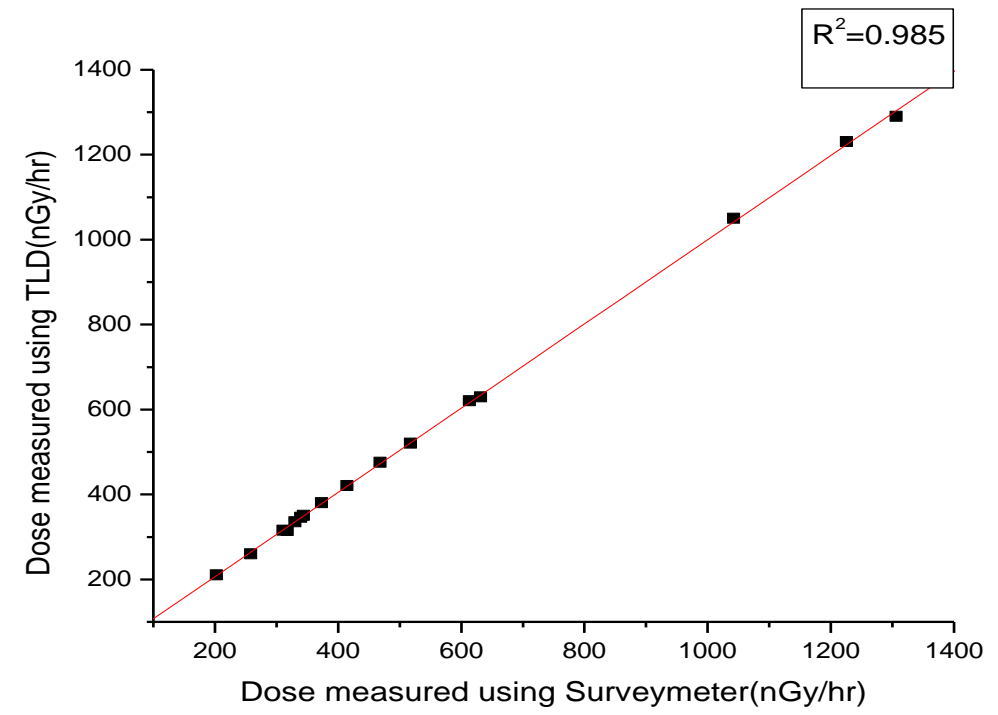

Figure 1: Correlation graph between gamma absorbed dose rates measured using Survey meter and TLDs

\subsection{Indoor to outdoor gamma dose ratio}

In this study, we obtained a geometric mean value of 0.58 for the indoor to outdoor dose ratio. The data obtained from the surveymeter reading were used to estimate the dose ratio. The ratio of indoor to outdoor gamma ray doses, in normal radiation background areas in India, is found to be approximately 1.2, particularly in houses which have tiled/cemented floors and concrete walls and ceilings [13] In another study, Chougaonkar et al. [8] have reported that the mean value of ratio was 0.8 for those dwellings which used construction materials such as bricks, cement, and masonry tiles, which were procured from a different region and these construction materials, had less radioactivity content than the surrounding soil.

\subsection{Comparison of dose measured by survey meter and TLDs}

The correlation between the dose rate values measured using TLD and portable survey meter is plotted in Fig. 1, which indicates a significant positive correlation $\left(\mathrm{R}^{2}=0.98\right)$ between the results of the two different methods. However, as indicated in the correlation plot, the agreement between the two techniques is good for low dose values and the deviation increases at higher dose values.

Table 2: The activity concentrations of ${ }^{226} \mathrm{Ra},{ }^{32} \mathrm{Th}$ and ${ }^{40} \mathrm{~K}, \mathrm{Ra}_{\text {eq }}$, dose rate, annual effective dose ,AGDE and external and internal hazard indices for the soil samples

\begin{tabular}{|c|c|c|c|c|c|c|c|c|c|c|c|c|c|}
\hline Location & $\begin{array}{l}\text { Sample } \\
\text { code }\end{array}$ & $\begin{array}{l}{ }^{226} \mathbf{R a} \\
(\mathrm{Bq} / \mathrm{kg})\end{array}$ & $\begin{array}{l}{ }^{232} \mathrm{Th} \\
(\mathrm{Bq} / \mathrm{kg})\end{array}$ & $\begin{array}{l}{ }^{40} \mathrm{~K} \\
(\mathrm{~Bq} / \mathrm{kg})\end{array}$ & $\begin{array}{l}\mathbf{R a}_{\mathrm{eq}} \\
(\mathbf{B q} / \mathbf{k g})\end{array}$ & $\begin{array}{l}\text { Dose } \\
\text { rate } \\
(\mathrm{nGy} / \mathrm{h})\end{array}$ & $\begin{array}{l}\text { Annual effective dose } \\
(\mathrm{mSv} / \mathrm{y})\end{array}$ & $\begin{array}{l}\text { AGDE } \\
(\mu S v / \\
y)\end{array}$ & $\mathbf{H}_{\text {ext }}$ & $\mathbf{H}_{\text {int }}$ & $\mathbf{I}_{\alpha}$ & $\mathbf{I}_{\gamma}$ & $\mathbf{I}_{\mathrm{r} \gamma}$ \\
\hline \multirow{15}{*}{ Thangasherry } & THA1 & 30.2 & 42.2 & 290.2 & 110.8 & 52.1 & 0.063 & 360.8 & 0.31 & 0.38 & 0.15 & 0.41 & 0.63 \\
\hline & THA2 & 33.2 & 40.2 & 295.2 & 111.3 & 52.4 & 0.064 & 363.3 & 0.31 & 0.39 & 0.16 & 0.41 & 0.62 \\
\hline & THA3 & 25.6 & 39.5 & 285.5 & 102.1 & 48.1 & 0.059 & 333.8 & 0.28 & 0.35 & 0.12 & 0.37 & 0.61 \\
\hline & THA4 & 29.5 & 35.6 & 250.2 & 97.9 & 46.1 & 0.056 & 318.5 & 0.26 & 0.34 & 0.14 & 0.35 & 0.54 \\
\hline & THA5 & 35.2 & 44.2 & 300.2 & 119.4 & 56.1 & 0.068 & 387.7 & 0.32 & 0.42 & 0.17 & 0.43 & 0.66 \\
\hline & THA6 & 35.2 & 45.2 & 295.6 & 120.5 & 56.5 & 0.069 & 390.5 & 0.33 & 0.42 & 0.17 & 0.44 & 0.67 \\
\hline & THA7 & 40.2 & 49.5 & 310.2 & 132.6 & 62.1 & 0.076 & 428.5 & 0.36 & 0.47 & 0.21 & 0.48 & 0.72 \\
\hline & THA8 & 25.6 & 41.2 & 284.5 & 104.4 & 49.1 & 0.061 & 340.6 & 0.28 & 0.35 & 0.12 & 0.38 & 0.61 \\
\hline & THA9 & 24.5 & 35.6 & 289.5 & 95.6 & 45.3 & 0.055 & 315.4 & 0.26 & 0.33 & 0.12 & 0.35 & 0.56 \\
\hline & THA10 & 29.5 & 38.4 & 295.5 & 105.1 & 49.6 & 0.061 & 344.4 & 0.28 & 0.36 & 0.14 & 0.38 & 0.61 \\
\hline & THA11 & 32.2 & 44.2 & 301.2 & 116.4 & 54.7 & 0.067 & 378.8 & 0.32 & 0.41 & 0.16 & 0.42 & 0.66 \\
\hline & THA12 & 33.5 & 45.2 & 210.2 & 112.8 & 52.2 & 0.064 & 358.4 & 0.31 & 0.39 & 0.16 & 0.41 & 0.61 \\
\hline & THA13 & 34.5 & 32.2 & 204.2 & 94.8 & 44.3 & 0.054 & 305.3 & 0.26 & 0.35 & 0.17 & 0.34 & 0.48 \\
\hline & THA14 & 35.5 & 42.2 & 198.2 & 109.7 & 50.7 & 0.062 & 348.3 & 0.31 & 0.39 & 0.17 & 0.39 & 0.57 \\
\hline & THA15 & 34.5 & 37.8 & 347.8 & 112.9 & 53.7 & 0.065 & 373.8 & 0.31 & 0.41 & 0.17 & 0.41 & 0.63 \\
\hline
\end{tabular}




\section{CONCLUSION}

The mean value of the gamma dose observed along the coastal region of Thangasherry was lower compared to the worldwide average value as well as all India average value. The mean value of total annual effective dose were 0.26 $\pm 0.01 \mathrm{mSv} \mathrm{y}^{-1}$ and $0.26 \pm 0.03 \mathrm{mSv} \mathrm{y}^{-1}$ respectively. The indoor to outdoor dose ratio had a mean value of 0.58 . A significant positive correlation was observed between the indoor and outdoor dose rates. A good correlation was observed between the gamma dose rate values measured using TLD and portable survey meter. The agreement between the two techniques is good for low dose values and the deviation increased at higher dose values. The mean activity concentrations of the soil samples are $35.2 \pm 5,45 \pm 5$ and $331.9 \pm 10 \mathrm{~Bq} / \mathrm{kg}$, respectively for ${ }^{226} \mathrm{Ra},{ }^{232} \mathrm{Th}$ and ${ }^{40} \mathrm{~K}$. The mean radium activity is higher than the world average. The radiological characteristics and radiological indices were estimated from the measured activity concentration values of these radionuclides. The mean value of $\mathrm{Ra}_{\mathrm{eq}}$ of the soil samples are $132.2 \pm 20 \mathrm{~Bq} / \mathrm{kg}$. For each sample, in this study, the representative level index has been determined to assess the radiological hazard of exposure of the public. The absorbed dose rate in air and the mean value of the representative level index are greater than the recommended level.

\section{REFERENCE}

[1] United Nations Scientific Committee on the Effects of Atomic Radiation(UNSCEAR).Report to the General Assembly, vol. 1, Annex. B;2008.

[2] Nambi KSV, Bapat VN, David M, Sundaram VK, Santa CM, Soman SD. Natural background radiation and population dose distribution in India. India: HPD,BARC; 1986.

[3] United Nations Scientific Committee on the effects of Atomic Radiation(UNSCEAR). Exposures resulting from nuclear explosions. New York, AnnexE: United Nations Publication; 1982.

[4] Chougaonkar MP, Shetty PG, Mayya YS, Puranik VD, Kushwaha HS.Performance characteristics of newly modified CaSO4:Dy based indigenous thermoluminescent dosimeters for environmental radiation monitoring. $J$ NuclSci Technol 2008(Suppl. 5):610-3.

[5] Lu, X. and Zhang, X (2006). Measurement of natural radioactivity in sand samples collected from the Baoji Weihe Sands Park, China. Environ. Geol. 50, 977-982 .

[6] Ramasamy, V., Suresh, G., Meenakshisundaram, V.and Ponnusamy, V. Horizontal and vertical characterization of radionuclides and minerals in river sediments. Appl. Radiat. Isot. 69, 184-195 (2011)

[7] Mamont-Ciesla, K., Gwiazdowski, B., Biernacka, M. andZak, A. Radioactivity of building materials in Poland. In:Vohra, G., Pillai, K. C. and Sadavisan, S., Eds. Natural Radiation Environment. Halsted Press, p. 551 (1982).

[8] Chougaonkar MP, Eappen KP, Ramachandran TV, Shetty PG, Mayya YS, Sadasivan S, Venkat S, Raj V. Profiles of doses to the population living in the high background radiation areas in Kerala, India. J Environ Radioact 2004;71:275-97

[9] United Nations Scientific Committee on the Effects of Atomic Radiation(UNSCEAR). Sources and effects of ionizing radiation. Report to the GeneralAssembly, Annexe B; 2000.

[10] Ramachandran TV. Review article on background radiation, people and the environment. Iran J Radiat Res 2011;9:63-76. 